\begin{tabular}{|c|c|c|}
\hline \multirow{3}{*}{$\begin{array}{r}\text { Case Reports in } \\
\text { Gastroenterology }\end{array}$} & \multirow{2}{*}{\multicolumn{2}{|c|}{ Case Rep Gastroenterol 2020;14:116-123 }} \\
\hline & & \\
\hline & $\begin{array}{l}\text { DOI: 10.1159/000506226 } \\
\text { Published online: April 2, } 2020\end{array}$ & $\begin{array}{l}\text { (c) } 2020 \text { The Author(s) } \\
\text { Published by S. Karger AG, Basel } \\
\text { www.karger.com/crg }\end{array}$ \\
\hline & $\begin{array}{l}\text { This article is licensed under } \\
\text { International License (CC BY-N } \\
\text { Usage and distribution for comm }\end{array}$ & $\begin{array}{l}\text { nons Attribution-NonCommercial } 4.0 \\
\text { ger.com/Services/OpenAccessLicense). } \\
\text { uires written permission. }\end{array}$ \\
\hline
\end{tabular}

\title{
Minor Papillary Relief in a Type IA Choledochal Cyst: A Case Report and Review of the Literature
}

\author{
Sindhura Kolli ${ }^{\mathrm{a}}$ Simcha Weissman ${ }^{\mathrm{b}}$ Emmanuel Ofori ${ }^{\mathrm{c}}$ \\ Khoi Paul Dang-Ho ${ }^{a}$ Praneeth Bandaru ${ }^{a}$ Kruthika Bachali ${ }^{a}$ \\ Evangelos Tsipotis ${ }^{c}$ Denzil Etienne ${ }^{c}$ Madhavi Reddy ${ }^{c}$ \\ Abraham Jelin ${ }^{c}$ Krishna Gurram ${ }^{c}$ \\ aDepartment of Medicine, The Brooklyn Hospital Center, Affiliate of The Icahn School of \\ Medicine at Mount Sinai, Brooklyn, NY, USA; ${ }^{b}$ Department of Medicine, Hackensack \\ Meridian Health-Palisades Medical Center, North Bergen, NJ, USA; 'Department of \\ Gastroenterology and Hepatology, The Brooklyn Hospital Center, Affiliate of The Icahn \\ School of Medicine at Mount Sinai, Brooklyn, NY, USA
}

\section{Keywords}

Type $1 \mathrm{~A}$ choledochal cyst · Roux-en-Y hepaticojejunostomy · Endoscopic retrograde cholangiopancreatography · Biliary anatomical variations · Cholangiocarcinoma · Biliary obstruction · Aberrant pancreaticobiliary junction

\section{Abstract}

Choledochal cysts are an anatomical conundrum as they present with nonspecific symptoms generally delaying diagnosis and treatment. Its lag time remains critical, as cholangiocarcinoma, a fatal sequelae, contributes to its morbidity and mortality. Herein, we present a case of a type $1 \mathrm{~A}$ choledochal cyst. We hope that its review on presentation, classification system, diagnosis, and management prevent complications and cataclysmic results. 


\section{Introduction}

Choledochal cysts (CC) are formed due to an abnormal pancreaticobiliary connection causing a reflux of pancreatic fluid into the bile duct. The repetitive assault will result in epithelial damage giving way to an abnormal cystic dilatation. The triad of symptoms of abdominal pain, jaundice, and right upper quadrant mass become less typical and perceivable with patients' age despite older patients' increased discernibility. This failure to successfully diagnose CC delays treatment and carries a variable but high risk of cholangiocarcinoma or more immediate sequelae such as jaundice, cholangitis, rupture, and biliary peritonitis. Current diagnostic algorithm involves an initial abdominal ultrasound (US) or endoscopic ultrasound (EUS), followed by endoscopic retrograde cholangiopancreatography (ERCP), which holds a dual diagnostic confirmation and therapeutic utility. It has been difficult to delineate them from pancreatic pseudocysts or primary sclerosing cholangitis without the help of ERCP. Due to the malignancy potential of a CC transforming into cholangiocarcinoma, treatment consists of the complete resection of the cyst and patency of bile duct outflow with a sphincterotomy and Roux-en-Y hepaticojejunostomy. This review of the literature of CC will highlight a case of CC with an unusual anatomical solution to ensure the patency of bile duct outflow, which is a key step in treatment.

\section{Case Presentation}

A 17-year-old African American male with no past medical history presented with acute sharp non-radiating epigastric abdominal pain. Signs included tenderness on palpation of epigastric area. Vitals and blood work including liver function tests and immature granulocytes were within normal limits. Given the severity of abdominal pain, magnetic resonance imaging was ordered and found a cystic dilatation within the pancreas. An EUS was performed and revealed a dilated extrahepatic biliary duct of $20 \mathrm{~mm}$ extending from the common hepatic duct down to the distal common bile duct (CBD) indicating a type $1 \mathrm{~A} \mathrm{CC}$ with choledocholithiasis, but no aberrant pancreaticobiliary junction (Fig. 1). An ERCP was performed (Fig. 2) and the CBD was unable to be cannulated via the major papilla, even with a 39Rx sphincterotome with 0.025 guidewire. Interestingly, there was a large amount of bile flowing from the minor papilla (Fig. 3). The minor papilla was then successfully cannulated with a 5-4-3 cannula. A subsequent cholangiogram/pancreatogram demonstrated a connection from the duct of Santorini (minor duct) to CC (Fig. 4). This represented a type IA CC with drainage only through the minor papilla. With the elevated risk for cholangiocarcinoma, the patient subsequently underwent a cyst excision with a Roux-en-Y hepaticojejunostomy. The patient recovered well with complete resolution of symptoms.

\section{Discussion}

First documented in 1723, CC are due to an abnormal pancreaticobiliary junction causing reflux of pancreatic fluid into the bile duct resulting in epithelial damage [1]. This would give way to an abnormal cystic dilatation within the hepatobiliary tract without evidence of an obstruction [2]. However, animal models have failed to reproduce this theory leaving its etiology unclear [3]. CC are predominantly found in the Asian population, with an incidence of 1/1,000 versus 1/150,000 in Caucasians, with a female preponderance of 4:1 [2]. While a majority of 
Kolli et al.: Minor Papillary Relief in a Type IA Choledochal Cyst: A Case Report and Review of the Literature

CC occur congenitally and present during childhood, approximately $25 \%$ are diagnosed in adulthood [4].

The first CC classification system was described in 1959 by Alonso-Lej et al. [5], defining three types of CC. In 1977, Todani et al. [6] later modified the classification system, revolving around the junction at which the cystic duct connects with the dilatation. It is currently the most widely accepted system to diagnose and guide treatment of CC $[1,6,7]$ (Fig. 5). Five types of CC have been classified: type I ( $50-80 \%$ of all CC), type II (2\%), type III (1.4-4.5\%), type IV (15-35\%), and type V (20\%) [9]. Type I CC are further subclassified into type IA, IB, and IC cysts [7]. Type IA cysts have the gallbladder directly originate from the cyst accompanied by a dilated extrahepatic biliary tree and a non-dilated intrahepatic biliary tree. Type IB cysts are focal dilatations of the CBD. Type IC cysts present with fusiform dilations of the common hepatic duct and CBD [6, 7]. Type II cysts are true diverticula of the CBD [10]. Cholangiography will show opacification of the diverticulum arising from the CBD, which can be confused with gallbladder duplication $[6,10]$. Type III CC, also known as choledochoceles, are identified by their location along the duodenal wall at the pancreaticobiliary junction [7]. Unlike other CC, choledochoceles are more evenly distributed among the sexes and have a lower risk of malignant transformation at $2.5 \%$.

Due to these differences, there are authors that contend that choledochoceles should not be classified as CC [7-10,11]. Type IV CC are the second most common type of cyst and are further classified into type IVA and IVB cysts. Type IVA cysts present with multiple cysts in both the intrahepatic and extrahepatic duct. Type IVB cysts present only in the extrahepatic duct $[7,11]$. Type V CC contain multiple dilations in the intrahepatic biliary ducts and are described as a string of beads appearance on contrast computed tomography (CT) [7, 11]. Type $\mathrm{V}$ has no extrahepatic involvement and is associated with polycystic kidney disease. If patients are additionally diagnosed with congenital hepatic fibrosis, then it is termed Caroli's syndrome and diagnosed by identifying the central dot sign, which is dilated intrahepatic bile ducts surrounding the portal vein on magnetic resonance cholangiopancreatography (MRCP) or contrast CT $[10,11,12]$. Visser et al. [4] disagrees with the modified Todani classification system stating that type I and IVA cysts are extensions of the same disease, determined by the extent of cystic dilation along the intrahepatic biliary tree. They suggest abandoning the Todani classification and adopting descriptive terminology to diagnose CC [9].

CC are more commonly diagnosed in childhood (75\%) and present atypically in adults as symptoms become less discernible [9]. The classic triad of symptoms, which include abdominal pain, jaundice, and right upper quadrant mass, are usually present in pediatric patients $[10,11]$. Adults are more likely to be asymptomatic or present only with abdominal pain [10]. Dilated cysts and distal strictures result in chronic inflammation, bile stasis, and stone formation leading to complications such as jaundice, pancreatitis, cholangitis, portal hypertension, and elevated liver function test results $[9,10,13]$. Biliary amylase levels may be elevated and are correlated with the severity of illness $[7,9,10]$. Rupture and biliary peritonitis can present in 1-2\% of pediatric patients, facilitating emergency biliary drainage [10].

Incidental findings of CC in adults occur in one-third of patients with the increase in available imaging modalities [14]. Initial diagnosis of CC begins noninvasively with an abdominal US depicting a dilated cystic mass of the bile duct or anomalous connections [5]. If intrahepatic dilatation is detected, then the gold standard method of ERCP or percutaneous transhepatic cholangiography (PTHC) must be performed to further delineation between type I and IV [7] (Fig. 6). Moreover, the advent of EUS has revolutionized the detection of intra-biliary pathology. EUS in addition to ERCP can be used in place of MRCP when unavailable. The distal and intraduodenal portions of the CBD, however, are beyond the reach of PTHC. Complications of 


\section{Case Reports in Gastroenterology}

Case Rep Gastroenterol 2020;14:116-123 DOI: 10.1159/000506226

(c) 2020 The Author(s). Published by S. Karger AG, Basel www.karger.com/crg

Kolli et al.: Minor Papillary Relief in a Type IA Choledochal Cyst: A Case Report and Review of the Literature

both ERCP and PTHC include pancreatitis from manipulation, cholangitis from the large amount of contrast needed, bleeding, and perforation [7, 15]. CT with contrast and CT cholangiography have a $90 \%$ sensitivity for diagnosis, but carry the risk of contrast and radiation along with cholangiography having poor illumination of the pancreatic duct [15]. Magnetic resonance imaging and MRCP have a sensitivity of $90-100 \%$ and do not carry the risks of contrast or radiation, but it will miss CC that are too small resulting in a higher number of false negatives $[6,7,15]$. This has led to ERCP as the current gold standard in both its diagnostic and therapeutic value in CC by capturing biopsies, papilla sphincterotomy, removal of cholelithiasis, and creating patent drainage [15]. Differential diagnosis includes biliary atresia that must be ruled out in neonates as a cause of obstructive jaundice, as well as lithiasis in any part of the biliary tract [7]. Biliary papillomatosis can present with a similar triad of symptoms, but is usually accompanied by gastrointestinal hemorrhage or hemobilia [17]. Pancreatic pseudocyst can be difficult to distinguish from CC. When a large cyst without accompanying biliary dilatation is present on imaging, it requires ERCP to effectively discriminate between them, a tool also crucial in differentiating between primary sclerosing cholangitis and CC [18].

Biopsies of the cyst wall display epithelial hyperplasia with round cell infiltration, bile duct wall thickening, and fibrosis, which are necessary to rule out intestinal metaplasia of the surrounding gallbladder, pancreas, or CBD. The risk of remnant biliary epithelial tissue undergoing malignant transformation is between 0.7 and 6\% [7]. The total incidence of malignancy in patients diagnosed with $\mathrm{CC}$ both preoperatively and postoperatively can range from 0.6 to $30 \%$ [7]. Chronic inflammation, pancreatic reflux, and biliary stasis are believed to play a role in the malignant transformation of CC $[7,9,10,19]$. Sites of malignant transformation tend to occur in any part of the biliary tract and dilated portions that have not yet undergone resection including the extrahepatic duct (50-62\%), gallbladder (38-46\%), and intrahepatic duct $(2.5 \%)$, or postoperatively occur in remnant biliary epithelium in the liver and pancreas $(0.7 \%)$ [9]. Malignant transformation takes years to develop requiring prolonged surveillance and occurs in mostly in type I (68\%) and type IV CC (21\%) with the remaining in descending order: type V (6\%), type II (5\%), and type III (1.6\%) [9]. Increasing age, obstructed cystic drainage, and incomplete cyst resection has been associated with increased risk of developing malignancy $[7,9,10,19]$.

Previously, patients would undergo cystenterostomy to treat CC, but when carcinoma was detected in $30 \%$ of patients, treatment guidelines changed and now aim for complete resection of the cyst and patency of bile duct outflow with a sphincterotomy and Roux-en-Y hepaticojejunostomy $[5,7,9]$. Excision of the cyst proximally is done to the point of normal proximal duct epithelium, while distal excision proximal to the pancreas can be complicated by pancreatitis [9]. If the cyst is intrahepatic as it can be in type IV or V, then excision is accompanied by hepatectomy and Roux-en-Y hepaticojejunostomy or even liver transplantation [6, $7,12]$.

In conclusion, cannulating minor papillae serves as a novel technique to ensure patency of bile flow as part of the treatment for CC. The risk of cholangiocarcinoma in unresected CC is $30 \%$, with that number increasing with age. With the availability of MRCP, ERCP, or EUS, identification of initial or recurrent carcinoma of the bile duct remnant hastens treatment. Patients with type I, II, or IV cysts are recommended to undergo surgical excision, while patients with type III cysts can be managed endoscopically [14, 19]. Regardless of type, the approach to CC is a multidisciplinary one. 
Kolli et al.: Minor Papillary Relief in a Type IA Choledochal Cyst: A Case Report and Review of the Literature

\section{Statement of Ethics}

This study was performed in accordance with the ethical standards of our institution. Patient consent was obtained for the case report.

\section{Disclosure Statement}

The authors declare no conflict of interest. The authors declare that they have no competing interests.

\section{Funding Sources}

The authors declare that this work was not supported by any grants or funding.

\section{Author Contributions}

Sindhura Kolli, Simcha Weissman, Emmanuel Ofori, Khoi Paul Dang-Ho, Praneeth Bandaru, Kruthika Bachali, Evangelos Tsipotis, and Denzil Etienne drafted the manuscript. Sindhura Kolli and Simcha Weissman provided critical revision. Madhavi Reddy, Abraham Jelin, and Krishna Gurram provided supervision and critical edits. Sindhura Kolli is the article guarantor. All authors agree to the final version of the manuscript.

\section{References}

1 Friedmacher F. Ford, K.E. Davenport, M. Choledochal malformations: global research, scientific advances and key controversies. Pediatr Surg Int. 2018;34:1-10.

2 Quintana A, Sathyanarayana SA. Type VI Choledochal Cyst: An Unusual Case of a Bile Duct Anomaly. Am Surg. 2018 Mar;84(3):462-5.

3 La Pergola E, Zen Y, Davenport M. Congenital choledochal malformation: search for a marker of epithelial instability. J Pediatr Surg. 2016 Sep;51(9):1445-9.

4 Visser BC, Suh I, Way LW, Kang SM. Congenital choledochal cysts in adults. Arch Surg. 2004 Aug;139(8):85560.

5 Alonso-Lej F, Rever WB Jr, Pessagno DJ. Congenital choledochal cyst, with a report of 2, and an analysis of 94 cases. Int Abstr Surg. 1959 Jan;108(1):1-30.

6 Todani T, Watanabe Y, Narusue M, Tabuchi K, Okajima K. Congenital bile duct cysts: Classification, operative procedures, and review of thirty-seven cases including cancer arising from choledochal cyst. Am J Surg. 1977 Aug;134(2):263-9.

7 Soares KC, Arnaoutakis DJ, Kamel I, Rastegar N, Anders R, Maithel S, et al. Choledochal cysts: presentation, clinical differentiation, and management. J Am Coll Surg. 2014 Dec;219(6):1167-80.

8 Kim OH, Chung HJ, Choi BG. Imaging of the choledochal cyst. Radiographics. 1995 Jan;15(1):69-88.

9 Bhavsar MS, Vora HB, Giriyappa VH. Choledochal cysts : a review of literature. Saudi J Gastroenterol. 2012 Jul-Aug;18(4):230-6.

10 Soares KC, Goldstein SD, Ghaseb MA, Kamel I, Hackam DJ, Pawlik TM. Pediatric choledochal cysts: diagnosis and current management. Pediatr Surg Int. 2017 Jun;33(6):637-50.

11 Martin RF. Biliary cysts: a review and simplified classification scheme. Surg Clin North Am. 2014 Apr;94(2):219-32.

12 Cha SW, Park MS, Kim KW, Byun JH, Yu JS, Kim MJ, et al. Choledochal cyst and anomalous pancreaticobiliary ductal union in adults: radiological spectrum and complications. J Comput Assist Tomogr. 2008 JanFeb;32(1):17-22. 
Kolli et al.: Minor Papillary Relief in a Type IA Choledochal Cyst: A Case Report and Review of the Literature

13 de Vries JS, de Vries S, Aronson DC, Bosman DK, Rauws EA, Bosma A, et al. Choledochal cysts: age of presentation, symptoms, and late complications related to Todani's classification. J Pediatr Surg. 2002 Nov;37(11):1568-73.

14 Senthilnathan P, Patel ND, Nair AS, Nalankilli VP, Vijay A, Palanivelu C. Laparoscopic management of choledochal cyst-technical modifications and outcome analysis. World J Surg. 2015 Oct;39(10):2550-6.

15 Drabek J, Keil R, Stovicek J, Lochmannova J, Hlava S, Snajdauf J, et al. The role of endoscopic retrograde cholangiopancreatography in choledochal cysts and/or abnormal pancreatobiliary junction in children. Prz Gastroenterol. 2017;12(4):303-9.

16 http://www.radiologyassistant.nl/en/p49e17de25294d/biliary-ducts-pathology.html 2019

17 Sen I, Raju RS, Vyas FL, Eapen A, Sitaram V. Benign biliary papillomatosis in a patient with a choledochal cyst presenting as haemobilia: a case report. Ann R Coll Surg Engl. 2012 Jan;94(1):e20-1.

18 Di Sena V, de Paulo GA, Macedo EP, Triviño T, Della Libera E, Ferrari AP. Choledochal cyst mimicking a pancreatic pseudocyst: case report and review. Gastrointest Endosc. 2003 Oct;58(4):620-4.

19 Ten Hove A, de Meijer VE, Hulscher JB, de Kleine RH. Meta-analysis of risk of developing malignancy in congenital choledochal malformation. Br J Surg. 2018 Apr;105(5):482-90.

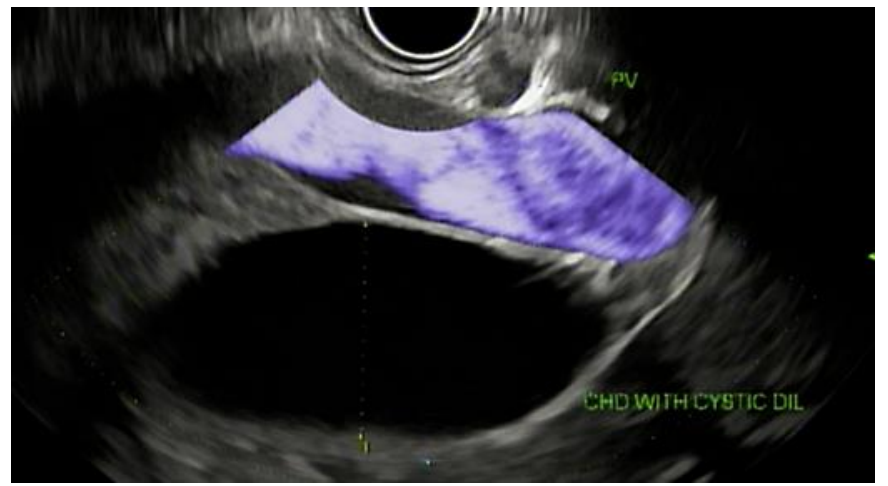

Fig. 1. Endoscopic ultrasound depicting common bile duct dilatation and the presence of a choledochal cyst.
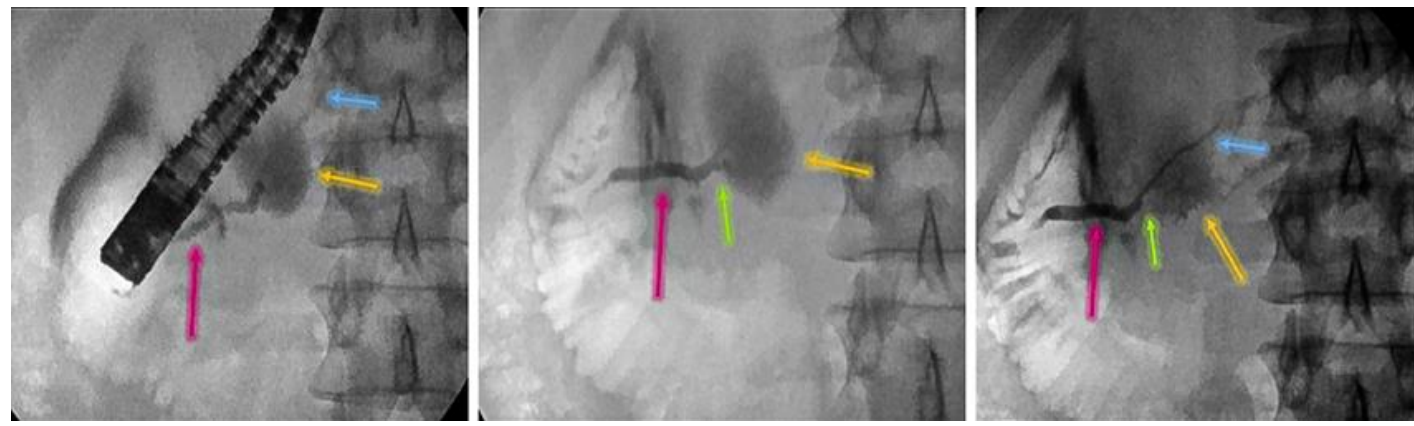

Fig. 2. Endoscopic retrograde cholangiopancreatography displaying the minor pancreatic duct (red), connection between minor duct and choledochal cyst (green), choledochal cyst (yellow), and pancreatic duct distal to the choledochal duct (blue), illustrating that as bile continued to flow from the choledochal cyst, the contrast opacification from the cyst decreased and subsequent loss of opacification between the connection from the pancreatic duct and the choledochal cyst occurred as well. 


\section{Case Reports in Gastroenterology}

\begin{tabular}{l|l}
\hline Case Rep Gastroenterol 2020;14:116-123 \\
\hline DOI: 10.1159/000506226 & $\begin{array}{l}\text { (c) 2020 The Author(s). Published by S. Karger AG, Basel } \\
\text { www.karger.com/crg }\end{array}$ \\
\hline
\end{tabular}

Kolli et al.: Minor Papillary Relief in a Type IA Choledochal Cyst: A Case Report and Review of the Literature

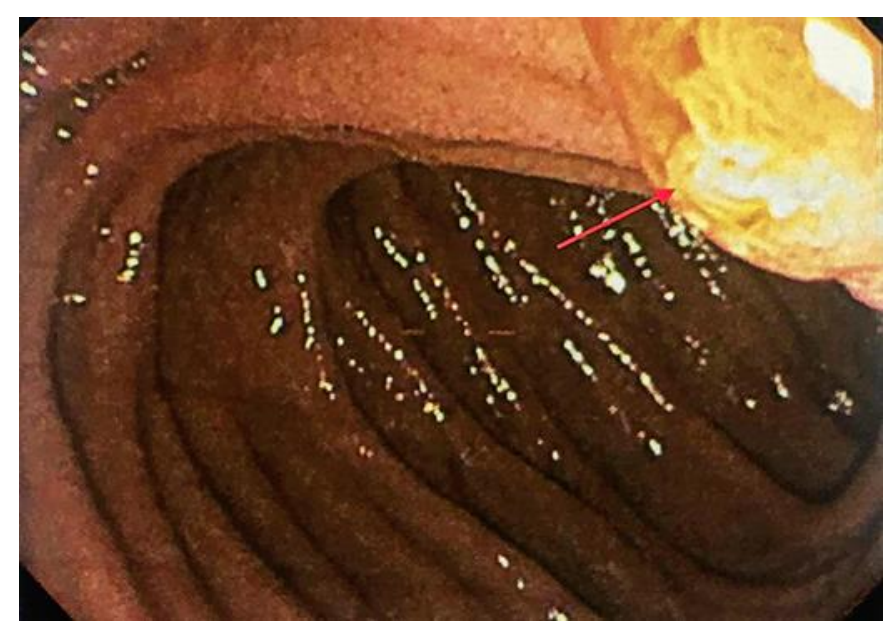

Fig. 3. Endoscopic image of bile flowing from minor papilla.

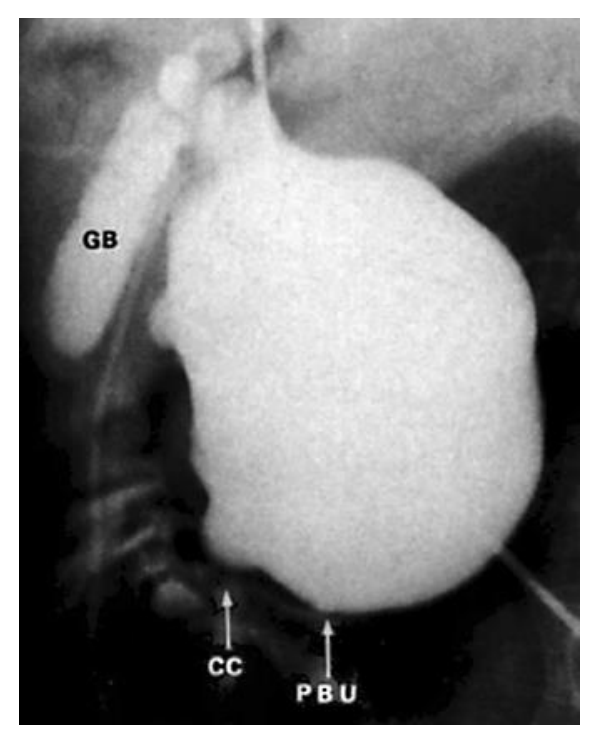

Fig. 4. Intraoperative cholangiogram showing cystic dilatation of the common bile duct indicating a type IA choledochal cyst. Reproduced with permission [8]. 


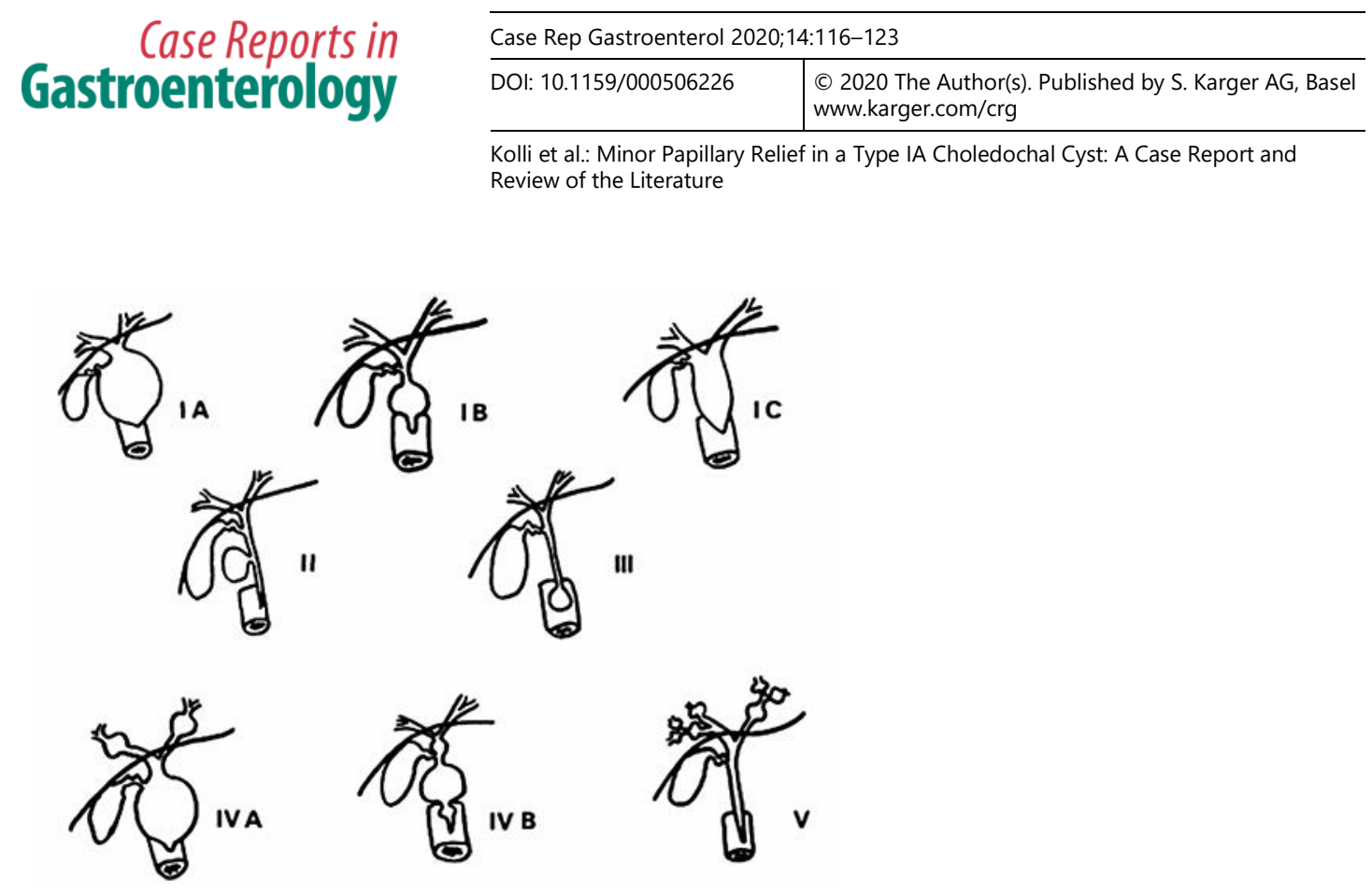

Fig. 5. Image depicting the Todani classification. Reproduced with permission [8].
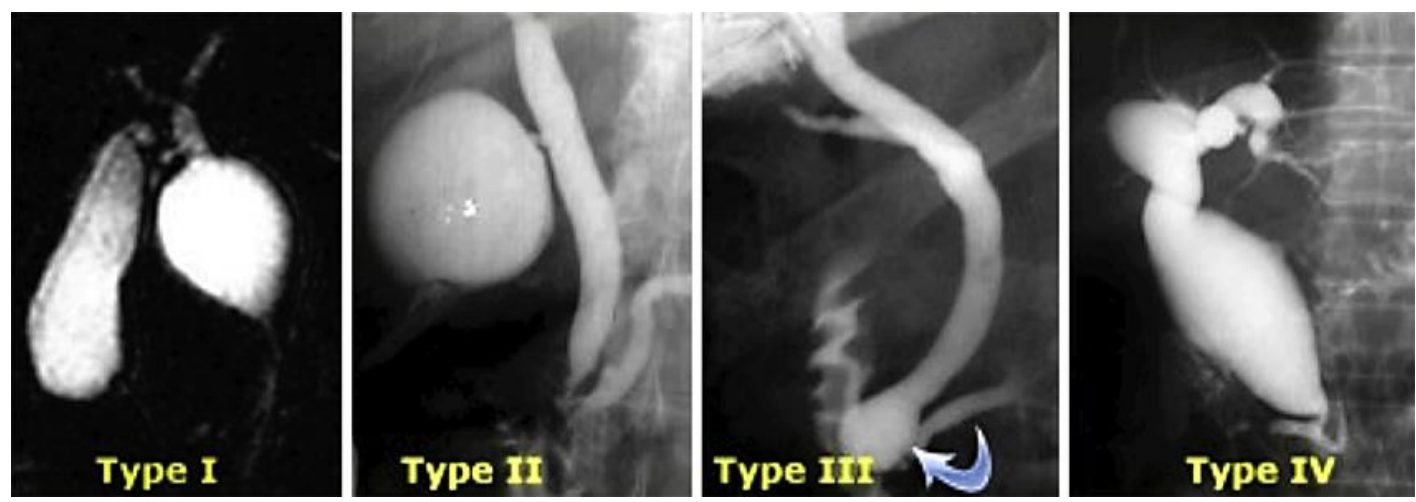

Fig. 6. MRCP images depicting choledochal cyst classification. Reproduced with permission [16]. 